\title{
Desirability Of Climate And The Spatial Allocation Of Migrants: A Statistical Inquiry
}

\author{
Stephen M. Renas and Rishi Kumar*
}

How important is climate as a factor influencing people's migration decisions? Although the number of scholarly studies dealing with the determinants of migration has grown substantially in recent years, the role of climate as a determinant of migration has not received the attention that it deserves. Only a few studies have examined in some detail the effect of climatic conditions on people's decisions to migrate (see Graves [2], [3], and Renas and Kumar [11] ). These studies have found that climate does play an important role in determining the spatial allocation of migrants. Still, several issues concerning the role of climate on the migration decision remain unexplored. The purpose of this paper is to examine some of these issues. In addition to determining which climate variables significantly affect migration flows, we assess the relative sensitivity of migration to climatic versus nonclimatic factors. Also, our statistical results are used to rank various locations according to the desirability of their climates. The basic model which is used in this study is described in section I. The empirical findings are presented in section II. Conclusions are found in section III.

\section{MODEL}

The basic model which is used in this study may be expressed as follows: $\mathbf{M}_{\mathrm{i}}=\mathrm{f}\left(\mathrm{INCOME}_{\mathrm{i}}, \mathrm{COST}_{\mathrm{i}}, \mathrm{INCCHG}_{\mathrm{i}}, \mathrm{COSTCHG}_{\mathrm{i}}, \mathrm{UNEMP}_{\mathrm{i}}\right.$, $\mathrm{EDUC}_{\mathrm{i}}, \mathrm{HDD}_{\mathrm{i}}, \mathrm{CDD}_{\mathrm{i}}, \mathrm{HUMID}_{\mathrm{i}}, \mathrm{WIND}_{\mathrm{i}}$, random errors)

where: $\quad M_{i}=$ net number of migrants into SMSA $\mathrm{i}$ between 1960 and 1970 expressed as a percentage of the 1960 population;

INCOME $_{i}=$ median family income in SMSA $\mathrm{i}$ in 1969;

$\operatorname{COST}_{\mathrm{i}}=$ annual cost in SMSA $\mathrm{i}$ of an intermediate budget for a four-person family, Spring 1969;

$\mathrm{INCCHG}_{\mathrm{i}}=$ annual rate of change of median family income in SMSA i between 1959 and 1969, expressed in percentage terms;

\footnotetext{
\#The authors wish to thank David Coberly for research assistance. They also wish to thank two anonymous referees for valuable suggestions. The authors alone are responsible for any errors.

*Department of Economics, Wright State University, Dayton, OH 45435.
} 
COSTCHG $_{1}=$ annual rate of change in the cost of living in SMSA $\mathrm{i}$ expressed in percentage terms; ${ }^{1}$

$\mathrm{UNEMP}_{\mathrm{i}}=$ unemployment rate of the civilian labor force in SMSA i in 1960;

$\mathrm{EDUC}_{\mathrm{i}}=$ median school years completed in 1960 for the population, twenty-five years old and over in SMSA i;

$\mathrm{HDD}_{\mathrm{i}}=$ annual heating degree days, $65^{\circ} \mathrm{F}$ base in SMSA $\mathrm{i}$ (this variable measures the sum of the negative departures of the daily mean temperature for each day of the year from a base of $65^{\circ} \mathrm{F}$. Days with average temperatures above $65^{\circ} \mathrm{F}$ do not add to or subtract from the yearly total);

$\mathrm{CDD}_{\mathrm{i}}=$ annual cooling degree days, $65^{\circ} \mathrm{F}$ base in SMSA $\mathrm{i}$ (this variable measures the sum of the positive departures of the daily mean temperature for each day of the year from a base of $65^{\circ} \mathrm{F}$. Days with average temperatures below $65^{\circ} \mathrm{F}$ do not add to or subtract from the yearly totals);

$\mathrm{HUMID}_{\mathrm{i}}=$ average relative humidity (percent) during June, July, and August in SMSA i; and

$\mathrm{WIND}_{\mathrm{i}}=$ average wind speed (m.p.h.) during December, January, and February in SMSA i.

It is expected that net in-migration to an area would be greater the larger median family income, the smaller the cost of living, the larger the rate of increase in median family income, the smaller the rate of increase in the cost of living, and the smaller the unemployment rate in the area.

It is difficult to assess on an a priori basis the effect of education on migration. A high level of educational attainment in an area may indicate a concentration of growth industries in that area since growth industries usually employ large numbers of highly educated personnel. On this basis, it is expected that net in-migration would be higher in an area in which educational attainment is high than in an area in which educational attainment is low (Pack [7]). On the other hand, individuals with high educational attainment may have a higher propensity to migrate (out of an area) than those with less education (Kau and Sirmans [5]. Miller [6], Pursell [8] ). Individuals with high levels of education are likely to have more employment opportunities elsewhere, may be in a better position to obtain information about destination areas, and may face lower risk when moving and, consequently, are more likely to move than those with less education. On this basis, an area in which educational attainment is high may experience a large amount of out-migration and, consequently, may have a low net in-migration rate. Greenwood [4], however, suggests that individuals with high levels of education may have more employment opportunities at home as well as away. He also suggests that there is no strong reason for believing that individuals are attracted to or repelled by areas with high levels of educational attainment. Whether a high level of educational attainment would increase or reduce the rate of net inmigration would depend on the relative strengths of the forces involved. 
It is expected that people by and large prefer an area which has a moderate climate to an area which has a very hot or a very cold climate, holding all other factors constant. If this is the case, then net in-migration to an area would be smaller the greater heating degree days (a measure of cold weather) and the greater cooling degree days (a measure of hot weather) in that area. Yet temperature factors alone may not determine how pleasant or unpleasant climate is. It is well known that humidity as well temperature can contribute to summer discomfort, and that the speed of the wind is a determining factor in how cold one "feels" in the winter. As a result, it is expected that net in-migration into an area would be smaller the greater HUMID, relative humidity during the summer, and the greater WIND, wind speed during the winter. ${ }^{2}$

\section{EMPIRICAL FINDINGS}

Regression Results

The equation found in the previous section, and variations of that equation, are estimated by OLS, and the results are presented in Table 1. Data sources are found in the Appendix. Equation (1) in Table 1 includes all of the nonclimate variables found in the equation in the previous section but none of the climate variables. The structure of equation (2) is similar to that of equation (1), except that in equation (2), INCOME and COST have been replaced by REAINC, real median family income, and INCCHG and COSTCHG have been replaced by REINCHG, or rate of change in real median family income. In equation (3), HDD and CDD have been added to the variables found in equation (1). Similarly, equation (4) includes all the variables found in equation (2) plus HDD and CDD. In equation (5), HUMID and WIND have been added to the variables found in equation (3). In equation (6), HUMID and WIND have been added to the variables found in equation (4).

A comparison of the various results in Table 1 demonstrates the effect of different specifications of the income and cost variables as well as the importance of climate in the migration decision. Generally speaking, the equations which include income and cost of living variables separately yield better results than the equations which include real income variables. This result is consistent with the findings of Renas [9] and Renas and Kumar [10] that inclusion of real labor market variables in a migration equation represent a misspecification.

Inclusion of climate variables greatly enhances the explanatory power of the regressions. Inclusion of $\mathrm{HDD}$ and $\mathrm{CDD}$ increases $\overline{\mathrm{R}}^{2}$ from .442 in equation (1) to .656 in equation (3). Addition of HUMID and WIND increases $\overline{R^{2}}$ to .688 in equation (5). Based on the value of $\bar{R}^{2}$ and the statistical significance of the explanatory variables, the equation which yields the best results is equation (5). In this equation, HDD, CDD, and WIND enter with the expected signs and are statistically significant. Although HUMID enters with the anticipated sign, it is not significant. The results suggest that, in general, people prefer areas that are not too cold, not too hot, and not too windy in the winter. Based on the findings, summer humidity does not play any role in the migration decision. 
The sensitivity of migration to climatic versus nonclimatic factors can be assessed by comparing beta (standardized regression) coefficients. A beta coefficient measures the number of standard deviation changes in the dependent variable that results from a one standard deviation change in an independent variable. The variable with the largest (unsigned) beta coefficient in equation (5) is HDD (beta $=.51963$ ), followed by INCCHG

TABLE 1

Regression Results

\begin{tabular}{|c|c|c|c|c|c|c|}
\hline \multirow{2}{*}{$\begin{array}{c}\text { Explanatory } \\
\text { Variables }\end{array}$} & \multirow[b]{2}{*}{ (1) } & \multirow[b]{2}{*}{ (2) } & \multicolumn{2}{|c|}{ Equation } & \multirow[b]{2}{*}{ (5) } & \multirow[b]{2}{*}{ (6) } \\
\hline & & & (3) & (4) & & \\
\hline CONSTANT & -43.946 & -35.324 & -3.8449 & -9.8684 & -20.896 & -17.646 \\
\hline INCOME & $\begin{array}{l}.00030 \\
(0.19)\end{array}$ & & $\begin{array}{l}.00116 \\
(0.83)\end{array}$ & & $\begin{array}{l}.00060 \\
(0.44)\end{array}$ & \\
\hline COST & $\begin{array}{l}-.00414^{\mathrm{b}} \\
(-1.72)\end{array}$ & & $\begin{array}{l}-.00508^{\mathrm{d}} \\
(-2.65)\end{array}$ & & $\begin{array}{l}-.00448^{c} \\
(-2.42)\end{array}$ & \\
\hline REAINC & & $\begin{array}{l}20.380 \\
(1.29)\end{array}$ & & $\begin{array}{l}33.727^{\mathrm{c}} \\
(2.44)\end{array}$ & & $\begin{array}{l}33.660^{c} \\
(2.35)\end{array}$ \\
\hline INCCHG & $\begin{array}{l}7.9937^{\mathrm{d}} \\
(2.67)\end{array}$ & & $\begin{array}{l}6.677 \mathrm{l}^{\mathrm{d}} \\
(2.63)\end{array}$ & & $\begin{array}{l}8.8637^{\mathrm{d}} \\
(3.32)\end{array}$ & \\
\hline COSTCHG & $\begin{array}{l}-.32034 \\
(-0.15)\end{array}$ & & $\begin{array}{l}1.2147 \\
(0.70)\end{array}$ & & $\begin{array}{l}2.6985 \\
(1.51)\end{array}$ & \\
\hline REINCHG & & $\begin{array}{l}4.6525^{\mathrm{d}} \\
(2.53)\end{array}$ & & $\begin{array}{l}2.6180 \\
(1.60)\end{array}$ & & $\begin{array}{l}2.3224 \\
(1.32)\end{array}$ \\
\hline UNEMP & $\begin{array}{l}-.66095 \\
(-0.64)\end{array}$ & $\begin{array}{l}-1.3593 \\
(-1.35)\end{array}$ & $\begin{array}{l}-1.9283^{c} \\
(-2.24)\end{array}$ & $\begin{array}{l}-2.5399^{d} \\
(-2.80)\end{array}$ & $\begin{array}{l}-1.7730^{\mathrm{c}} \\
(-2.13)\end{array}$ & $\begin{array}{l}-2.4740^{\mathrm{d}} \\
(-2.56)\end{array}$ \\
\hline E.DUC $^{\mathrm{a}}$ & $\begin{array}{l}4.4453^{d} \\
(2.80)\end{array}$ & $\begin{array}{l}2.2982 \\
(1.50)\end{array}$ & $\begin{array}{l}3.1727^{\mathrm{b}} \\
(2.39)\end{array}$ & $\begin{array}{l}.84022 \\
(0.63)\end{array}$ & $\begin{array}{l}4.1718^{\mathrm{d}} \\
(3.00)\end{array}$ & $\begin{array}{l}1.1817 \\
(0.80)\end{array}$ \\
\hline HDD & & & $\begin{array}{l}-.00324^{\mathrm{d}} \\
(-4.44)\end{array}$ & $\begin{array}{l}-.00307^{\mathrm{d}} \\
(-3.61)\end{array}$ & $\begin{array}{l}-.00221^{b} \\
(-2.01)\end{array}$ & $\begin{array}{l}-.00243^{\mathrm{b}} \\
(-1.77)\end{array}$ \\
\hline CDD & & & $\begin{array}{l}-.00469^{d} \\
(-2.78)\end{array}$ & $\begin{array}{l}-.00296 \\
(-1.59)\end{array}$ & $\begin{array}{l}-.00381^{\mathrm{b}} \\
(-1.79)\end{array}$ & $\begin{array}{l}-.00188 \\
(-0.72)\end{array}$ \\
\hline HUMID & & & & & $\begin{array}{l}-.09642 \\
(-0.71)\end{array}$ & $\begin{array}{l}.06971 \\
(0.43)\end{array}$ \\
\hline WIND & & & & & $\begin{array}{l}-1.3661^{\mathrm{b}} \\
(-1.75)\end{array}$ & $\begin{array}{l}-.53399 \\
(-0.58)\end{array}$ \\
\hline SEE & 6.75 & 7.42 & 5.31 & 6.18 & 5.06 & 6.36 \\
\hline$\overline{\mathrm{R}}^{2}$ & .442 & .327 & .656 & .533 & .688 & .506 \\
\hline
\end{tabular}

NOTE: $t$-values are given in parentheses below the respective coefficients. SEE is the standard error of estimate; $\mathrm{R}^{2}$ is the coefficient of determination adjusted for degrees of freedom.

aTests of significance on EDUC utilize a two-tail test; tests of significance on all other variables utilize a one-tail test.

${ }^{\mathrm{b}}$ Significant at the .05 level.

'Significant at the .025 level.

'Significant at the .01 level. 
$($ beta $=.49419)$, EDUC $($ beta $=.39665)$, CDD $($ beta $=.39207)$, COST $($ beta $=.33190)$, WIND $($ beta $=.29305)$, UNEMP $($ beta $=.26374)$, COSTCHG $($ beta $=.20367)$, HUMID $($ beta $=.08681)$, and INCOME $($ beta $=.06576)$. Thus, in making migration decisions, people are most sensitive to heating degree days (a measure of cold weather), followed by the rate of change in income, the level of educational attainment, cooling degree days (a measure of hot weather), the cost of living, winter wind speed, the unemployment rate, the rate of change in the cost of living, summer humidity, and median family income.

\section{Ranking of SMSAs According to Desirability of Climate}

It is possible, by using the regression results, to rank the various SMSAs according to the desirability of their climates. Equation (5), which yields the best overall results, is used to perform the ranking. In equation (5), HUMID is statistically insignificant and hence is not considered in determining the ranking. That portion of equation (5) which reflects the contribution of a city's climate to its net in-migration rate, holding all other factors constant, is -.00221 HDD -.00381 CDD - 1.3661 WIND. A city whose climate makes a large contribution to its net in-migration rate, after controlling for other factors, can be considered to have a more desirable climate than a city whose climate makes a smaller contribution to its net in-migration rate. The value of the contribution of each city's climate to its net in-migration rate was computed using the expression above. The more

TABLE 2

Ranking of SMSAs According to

Desirability of Climate

\begin{tabular}{lclc}
\hline \multicolumn{1}{c}{ SMSA } & Rank & \multicolumn{1}{c}{ SMSA } & Rank \\
\hline San Diego, Cal. & 1 & New York, N.Y. & 18 \\
San Francisco, Cal. & 2 & St. I.ouis, Mo. & 19 \\
I.os Angeles, Cal. & 3 & Dallas. Tex. & 20 \\
Bakersfield, Cal. & 4 & Indianapolis, Ind. & 21 \\
Durham, N.C. & 5 & Dayton, Ohio & 22 \\
Houston, Tex. & 6 & Pittsburgh, Pa. & 23 \\
Seattle, Washin. & 7 & Kansas City, Mo. & 24 \\
Orlando, Fla. & 8 & Cedar Rapids, Ia. & 25 \\
Baton Rouge, La. & 9 & Chicago, Ill. & 26 \\
Nashville, Tenn. & 10 & Detroit, Mich. & 27 \\
Atlanta, Ga. & 11 & Cleveland, Ohio & 28 \\
Cincinnati, Ohio & 12 & Green Bay, Wis. & 29 \\
Washington, D.C. & 13 & Wichita, Kans. & 30 \\
Denver, Colo. & 14 & Champaign-Urbana, Ill. & 31 \\
Austin, Tex. & 15 & Minneapolis-St. Paul, Minn. & 32 \\
Baltimore, Md. & 16 & Milwaukee, Wis. & 33 \\
Philadelphia, Pa. & 17 & & 34 \\
\hline
\end{tabular}


negative the value of the expression, the less desirable climate is. Hence, computing the value of the expression for each SMSA allows a ranking of the SMSAs according to the desirability of their climates. The numbers $-.00221,-.00381$, and -1.3661 can be thought of as the weights which are applied to $\mathrm{HDD}, \mathrm{CDD}$, and WIND, respectively, in order to determine the desirability (or lack of desirability) of climate.

The ranking that results from this procedure is found in Table 2. As can be seen, the SMSAs that rank highest in terms of desirability of climate tend to be those which have temperate or warm climates, and the SMSAs that rank lowest typically are those which have cold climates. In general, the ranking is consistent with the commonly held notions concerning climatic desirability. However, the relative ranking of several of the cities, Houston and Dallas in particular, deserves some explantion. Houston, a hot and humid city, ranks sixth in the list, whereas Dallas ranks twentieth. The explanation for this relative ranking is easy to provide. Although Houston is more humid in the summer than Dallas (77 percent relative humidity versus 64 percent), the results in equation (5) indicate that humidity is not statistically significant and, therefore, should not be considered in performing the ranking. Houston is ranked higher than Dallas in terms of climatic desirability in part because Houston is not as cold in the winter as Dallas (Houston has 1434 winter heating degree days, whereas Dallas has 2290). In addition, the average winter wind speed in Dallas, 11.7 m.p.h., is greater than in Houston, 8.1 m.p.h. ${ }^{3}$

\section{CONCLUSIONS}

In this paper, we examined empirically the importance of natural climate on the decision to migrate. It was found that individuals, in making locational decisions, generally prefer areas which have climates that are neither too hot nor too cold. They also prefer areas which do not have strong winter winds. The results are consistent with the findings of some other studies that individuals have a preference for a moderate, or temperate climate (see Alperovich et al. [1] and Kau and Sirmans [5] ). Using the statistical results, we were able to rank various SMSAs according to the desirability of their climates. Generally speaking, the SMSAs that ranked highest in terms of climatic desirability are those located in the western and southern United States.

\section{FOOTNOTES}

\footnotetext{
${ }^{1}$ This variable is based on the change in the annual cost of an intermediate budget for a four-person family rather than on the change in the Consumer Price Index for specific areas because budget data are available for thirty-nine SMSAs, whereas CPI data are available for only twenty-three to twenty-five SMSAs in the relevant period.

${ }^{2}$ We also experimented with a variable which measures wind speed during the summer; this variable was not statistically significant.

${ }^{3}$ In equation (5) (as well as in equation (6)) of Table 1 , the summer heat and humidity variables appear separately, as do the winter cold and wind speed variables.
}

Such a specification implies that summer heat and humidity independently affect summer discomfort and, similarly, that winter cold and wind speed independently affect winter discomfort. However, it may be argued that it is the interaction of summer heat and humidity, and winter cold and wind speed, which determines climatic discomfort. The interaction of summer heat and humidity is reflected in the Temperature-Humidity Index. The Temperature-Humidity Index is calculated from temperature and humidity, but is not a linear combination of these variables. The interaction of winter cold and wind speed is reflected in the Wind Chill Equivalent Temperature. The Wind Chill Equivalent Temperature is com- 
puted from temperature and wind speed, but like the Temperature-Humidity Index, is not a linear combination of its determinants.

In the equation below, $\mathrm{TH}$ is the absolute deviation of the average Temperature-Humidity Index during June, July, and August from 65. CHILL is the absolute deviation of the average Wind Chill Equivalent Temperature during December, January, and February from 65.

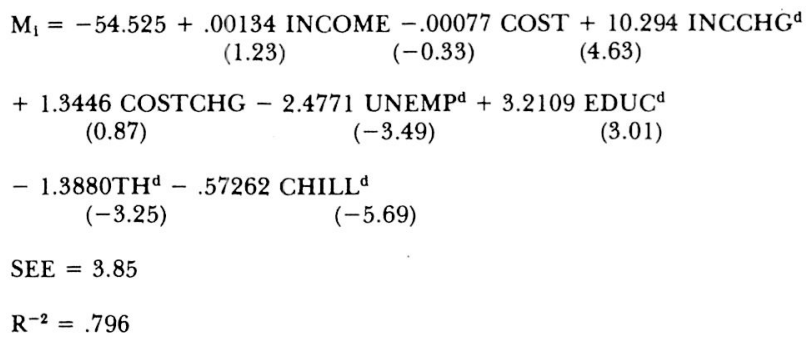

The notation employed here is the same as that found in Table 1. Seven SMSA's (including Houston) had to be dropped from the sample before this equation could be estimated because the Temperature-Humidity Index and the Wind Chill Equivalent Temperature could not be computed for some of the temperatures which were encountered. A ranking of the remaining cities accord-

ing to climatic desirability was performed using this equation. The ranking, however, did not appear as reasonable as the ranking which resulted from using equation (5) in Table 1. The new ranking suggested, for example, that Pittsburgh has a more desirable climate than Nashville.

\section{APPENDIX}

\section{Data Sources}

U.S. Bureau of the Census, Census of Population and Housing: 1970, General Demographic Trends for Metropolitan Areas, 1960 to 1970, Final Report PHC (2)-1, United States, 1971 , Table 11.

INCOME, INCCHG

COST

COSTCHG

UNEMP, EDUC

All Climate Variables
U.S. Bureau of the Census, Statistical Abstract of the United States: 1972, Section 33-Metropolitan Area Statistics.

U.S. Bureau of Labor Statistics, Three Budgets for an Urban Family of Four Persons, 1969-70, Supplement to Bulletin 1570-5, 1972, Table B-1.

U.S. Bureau of Labor Statistics, Three Standards of Living for an Urban Family of Four Persons, Spring 1967, Bulletin No. 1570-5, Table 1 and U.S. Bureau of Labor Statistics, Three Budgets for an Urban Family of Four Persons, 1969-70, Supplement to Bulletin 1570-5, Table A-2.

U.S. Bureau of the Census, County and City Data Book: 1962, Table 3.

National Oceanic and Atmospheric Administration data.

\section{REFERENCES}

1. Alperovich, G., J. Bergsman and C. Ehemann, "An Econometric Model of Migration Between US Metropolitan Areas," Urban Studies, Vol. 14 (1977), pp. $135-145$.

2. Graves, P.E., "Income and Migration Revisited," Journal of Human Resources, Vol. 14 (1979), pp. 112 121.

3. - "A Life-Cycle Empirical Analysis of Migration and Climate, by Race," Journal of Urban Economics, Vol. 6 (1979), pp. 135-147.
4. Greenwood, M. J., "An Analysis of the Determinants of Geographic Labor Mobility in the United States," Review of Economics and Statistics, Vol. 51 (1969), pp. 189-194.

5. Kau, J. B. and C. F. Sirmans, "A Recursive Model of the Spatial Allocation of Migrants," Journal of Regional Science, Vol. 19 (1979), pp. 47-56.

6. Miller, E., "Is Out-Migration Affected by Economic Conditions," Southern Economic Journal, Vol. 39 (1973), pp. 396-405. 
7. Pack, J. R. "Determinants of Migration to Central Cities," Journal of Regional Science, Vol. 13 (1973), pp. 249-260.

8. Pursell, D. E., "Age and Educational Dimensions in Southern Migration Patterns, 1965-1970," Southern Economic Journal, Vol. 44 (1977), pp. 148-154

9. Renas, S. M., "An Empirical Note on the TieboutTullock Hypothesis: Comment," Quarterly Journal of Economics, Vol. 94 (1980), pp. 619-623.
10. and R. Kumar, "The Cost of Living, Labor Opportunities, and the Migration Decision: A Case of Misspecification?: Reply," Annals of Regional Science. Vol. 13 (1979), pp. 106-108.

11. "An Econometric Examination of Clima tic Conditions and Migration," presented at the International Atlantic Economic Conference, Freeport/ Lucaya, Bahamas, February 11, 1980. 